Louisiana State University

LSU Digital Commons

Faculty Publications

Department of Geology and Geophysics

4-16-2020

\title{
Energetics of Interfacial Interactions of Hydrocarbon Fluids with Kerogen and Calcite Using Molecular Modeling
}

\author{
Zelong Zhang \\ Louisiana State University \\ Haoran Liu \\ Louisiana State University \\ Jianwei Wang \\ Louisiana State University
}

Follow this and additional works at: https://digitalcommons.Isu.edu/geo_pubs

\section{Recommended Citation}

Zhang, Z., Liu, H., \& Wang, J. (2020). Energetics of Interfacial Interactions of Hydrocarbon Fluids with Kerogen and Calcite Using Molecular Modeling. Energy and Fuels, 34 (4), 4251-4259. https://doi.org/ 10.1021/acs.energyfuels.0c00053

This Article is brought to you for free and open access by the Department of Geology and Geophysics at LSU Digital Commons. It has been accepted for inclusion in Faculty Publications by an authorized administrator of LSU Digital Commons. For more information, please contact ir@lsu.edu. 


\title{
Energetics of Interfacial Interactions of Hydrocarbon Fluids with Kerogen and Calcite Using Molecular Modeling
}

\author{
Zelong Zhang,* Haoran Liu, and Jianwei Wang
}

Cite This: Energy Fuels 2020, 34, 4251-4259

Read Online

ABSTRACT: Understanding of the fluid-rock interactions is essential to characterize the behavior of petroleum fluids in reservoir formations. Such knowledge is difficult to obtain due to the heterogeneous nature of hydrocarbon systems. This study investigated the interactions of light oil molecules with kerogen and calcite using molecular dynamics simulations. Specifically, octane and octanthiol were used as model molecules for non-polar and polar oil compounds; a kerogen fragment molecule was employed as the building block for kerogen, the major constituent of reservoir rock organics; calcite was used as a model system for hydrophilic materials in reservoir rocks. Umbrella sampling method combined with the weighted histogram analysis method was deployed to calculate the free energy profiles of oil molecule interactions with kerogen and calcite surfaces. The effects of surface composition, oil molecular polarity, surface water, and size of the oil molecular cluster on the interfacial interactions were evaluated based on the free energy profiles. The results show that the minimal energy required to recover oil molecules significantly decreases at both kerogen and calcite surfaces if water is presented. The kerogen surface exhibits stronger binding energies with oil molecules than that of the calcite. These findings suggest that (1) polar oil compounds require more effort to be recovered from the reservoir rocks than nonpolar molecules, (2) isolated oil molecules or oil clusters of a smaller size are harder to be displaced from the surfaces than a larger size of molecular clusters, and (3) the presence of water reduces the effort to recover oil at both surfaces. The results provide an energetic perspective of the interfacial interactions for the oil recovery in reservoir formations. This study demonstrates the capability of MD simulations in evaluating the energetics of the oil-rock interactions under different interface conditions, which can provide valuable implications for developing novel technologies of oil recovery.

\section{INTRODUCTION}

Oil is the main energy source for our modern civilization and will remain as a major contributor of global energy in the foreseeable future. ${ }^{1}$ However, only a portion of oil preserved in a reservoir can be recovered. Thus, it is imperative to improve the recovery efficiency of petroleum reservoirs. Current methods to improve oil production including primary, secondary, and tertiary oil recovery techniques can yield $30 \%-60 \%$ of the original oil in place, leaving up to $70 \%$ of the original oil in a reservoir., ${ }^{1,2}$

The pressing demand of energy for modern civilization has spurred technical innovations to improve oil recovery, especially through tertiary oil recovery or enhanced oil recovery. However, there is a limited understanding of how hydrocarbon-bearing fluids interact with the materials in reservoir formations. This knowledge gap impairs the assessment of the economic potential of a hydrocarbon reservoir. For example, relative permeability, an essential parameter of fluid flow characteristics for formation evaluation, is measured by special core analysis (SCAL) through conducting flow experiments on core plugs taken from a reservoir. However, SCAL results are often contradictory or cannot be properly implemented in the reservoir modeling and petrophysical evaluation. $^{3-5}$ A myriad of factors may complicate the results, including the hydrofracture geometries, networks of preexisting fractures, adsorption and desorption processes, non-Darcy multiphase flow, chemically and structurally heterogeneous formations, etc. ${ }^{6}$

The interfacial interactions between the fluid and rock play a key role in all these complications. As shown in Figure 1, if a pore has a less than $100 \mathrm{~nm}$ radius and the intermolecular interaction has an effective distance of $3 \mathrm{~nm}$, a significant portion $(12 \%-100 \%$ volume $)$ of confined fluid can be directly affected by the interfacial interactions. Therefore, to further improve recovery efficiency, a fundamental understanding of the fluid-rock interactions is indispensable.

To probe the interfacial interactions at the nanoscale, molecular-level characterization is necessary. Both experimental and computational approaches have been applied to study the hydrocarbon fluid behavior in the rock at the nanoscale. Extensive experimental studies have been conducted on the reservoir formations to characterize the organic content, ${ }^{7,8}$ pore structure, ${ }^{9-12}$ and petrophysical properties. ${ }^{11,13-15}$ These studies aimed to calibrate the empirical models in reservoir engineering to describe the fluid flow ${ }^{16,17}$ and to provide a basis for reservoir assessment and production optimization. ${ }^{18}$

Received: January 5, 2020

Revised: $\quad$ March 6, 2020

Published: March 9, 2020 


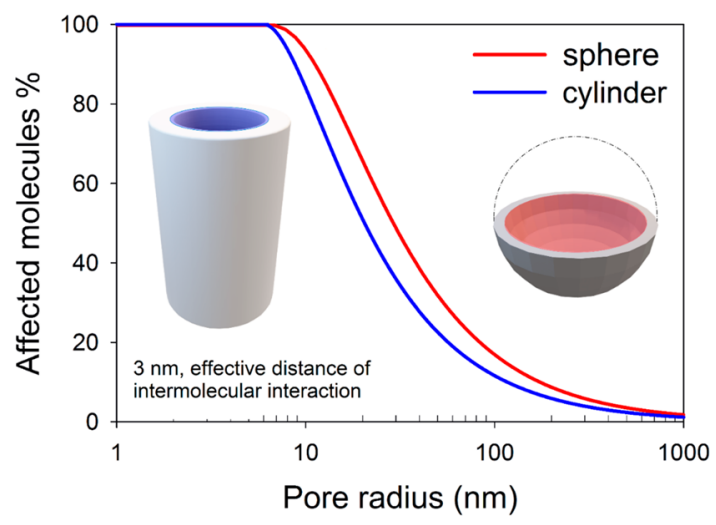

Figure 1. Effect of intermolecular interaction on the fluid confined in nanostructures.

However, due to the compositional and structural heterogeneity of reservoir formations, it is challenging to interpret the dynamics and kinetics of interface interactions without knowing the molecular scale details. Current understanding of the hydrocarbon systems heavily relies on characterization technologies to conduct experiments on surfaces and interfaces $^{19-21}$ such as focus ion beam scanning electron microscopy (FIB-SEM), ${ }^{15,22,23}$ transmission electron microscopy (TEM), ${ }^{23,24}$ atomic force microscopy (AFM), ${ }^{16,25,26} \mathrm{X}$ ray diffraction (XRD), ${ }^{27,28} \mathrm{X}$-ray microtomography (Micro$\mathrm{CT}),{ }^{29,30}$ nuclear magnetic resonance (NMR), ${ }^{31,32}$ etc. Implementing these methodologies to characterize microscopic phenomena becomes challenging at the molecular level. Unlike experiments, computational simulations can study physical phenomena over a range of scales, ${ }^{33}$ directly connecting the microscopic details of a system to macroscopic properties of experimental interest. ${ }^{34}$ Due to the intensive computation, quantum mechanics (QM) simulations have strict limits on the size, time, and complexity of the systems. $^{33-35}$ Molecular simulations, built on classical molecular mechanics (MM) such as Monte Carlo (MC) and molecular dynamics (MD), are more appropriate than QM methods to address the issues of size and complexity of the hydrocarbon systems. MC methods are a stochastic approach, suitable for system equilibrium, while MD techniques are deterministic, suitable for both equilibrium and transport properties of a given system. ${ }^{34,35}$ Thus, this study used MD to investigate the energetics of fluid-rock interactions. Currently, there are several studies using MD to investigate hydrocarbon fluid interactions with kerogen and minerals, such as (1) the adsorption, diffusion, and permeation of hydrocarbon fluid in shale kerogen and kerogen analogue; $;^{36-43}$ (2) slippage, displacement, and adsorption of hydrocarbon flow on quartz, calcite slits, and montmorillonite slits; ${ }^{44-47}$ (3) detachment of oil cluster from silicate surfaces in surfactant solution. ${ }^{48}$ These studies evaluated the effect of nanopores on the properties of hydrocarbon fluid, such as bulk viscosity, contact angle, and slippage with focuses on the phenomena of the interactions. For instance, Liu et al. in 2012 stated that water can penetrate the oil-water interface and form a surface water layer on a hydrophilic silica surface, enhancing the oil detachment from the hydrophilic surface. ${ }^{48}$ However, there is a lack of direct approaches to assess the energetics of these interactions, leaving the energetic aspect largely underexplored. Knowledge on energetics, such as the interaction thermodynamics, can improve the understanding of the fundamental mechanism in hydrocarbon fluids interactions with reservoir formations.

The present study intends to examine the feasibility of the computational approach to evaluate the free energy profile of the interactions between oil compounds and the surfaces of reservoir rock materials. Umbrella sampling, widely used in computational biology and biochemistry, ${ }^{49}$ was adopted to compute the free energy profiles of the oil interactions with the rock materials. We studied the surfaces of kerogen and calcite to evaluate the effect of four different variables including oil polarity (polar vs non-polar oil), oil cluster size (a single molecule oil vs 30 molecules oil cluster), surface composition (inorganic calcite mineral vs organic kerogen), and surface water (the presence vs the absence of surface water). Probing the free energy changes in oil-rock interactions can provide insight into the thermodynamics of the surface wettability and hydrocarbon behaviors in reservoir formations.

\section{METHODS}

Molecular Models for Oil, Kerogen, and Calcite. Crude oil is a mixture of a wide range of polar and non-polar compounds with varying proportions, compositions, and molecular weights. Typically, crude oil contains over $45 \%$ non-polar (e.g., alkanes and cycloalkanes) and less than $15 \%$ polar species (e.g., $\mathrm{N}$-, S-, O-, and metal-containing compounds). ${ }^{50,51}$ Polar components can significantly affect properties of hydrocarbon fluid in a reservoir such as viscosity, contact angle, interfacial activity, emulsion, and chemical stability. ${ }^{52-54}$ The oilrock interactions are largely attributed by the polar species, ${ }^{55}$ particularly in organic phases that usually retain more polar components than minerals. ${ }^{52}$ Thioalkanes are common sulfur compounds found in crude oils. ${ }^{56}$ Crude oil, especially from shale, can have a high content of light oil $\left(\mathrm{C}_{1}-\mathrm{C}_{9}\right){ }^{37,58}$ Therefore, we selected 1-octanethiol $\left(\mathrm{C}_{8} \mathrm{H}_{18} \mathrm{~S}\right)$ with a dipole moment of $2.9 \mathrm{D}^{59}$ and its non-polar counterpart $n$-octane $\left(\mathrm{C}_{8} \mathrm{H}_{18}\right)$ as the models for polar and non-polar oil, respectively, in our simulations, as shown in Figure 2. In addition, to model a small oil drop, we prepared two oil clusters
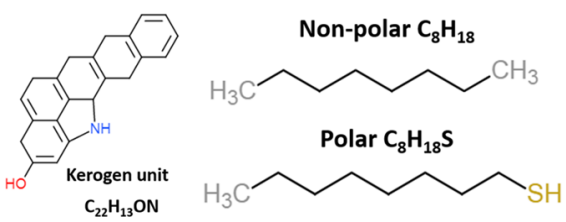

Figure 2. Molecular structure of type II kerogen fragment (left), nonpolar oil $n$-octane (right top), and polar oil 1-octanethiol (right bottom).

consisting of 30 molecules of octanethiol and octane for polar and non-polar oil droplets, respectively, as shown in Figure 3c.

Reservoir rocks have complex microstructures and mineralogy and contain various amount of inorganic and organic constituents. Major mineral phases include clays, quartz, and carbonates (calcite and dolomite).$^{60}$ Due to its simple structure and ubiquitous presence in formation rocks, the calcite (104) face was chosen as a model for hydrophilic surface of reservoir rocks. The calcite (104) is a flat stoichiometric surface. It is one of the most common mineral faces occurring in both geological and biological systems and has been well studied both computationally and experimentally. ${ }^{61}$ The key organic phase in shale involved in the interactions with hydrocarbon fluid is kerogen. ${ }^{52,62,63}$ Despite the complexity of kerogen in reservoir formations, ${ }^{64}$ many studies used graphene to represent kerogen. $^{36,42,43,65-68}$ The differences between graphene and kerogen, such as bonding environment of functional groups ${ }^{69,70}$ and surface morphology ${ }^{64}$ give rise to different chemical and mechanical properties and interfacial interactions. These deviations can lead to inaccurate modeling with respect to experimental measurements. ${ }^{70,71}$ 


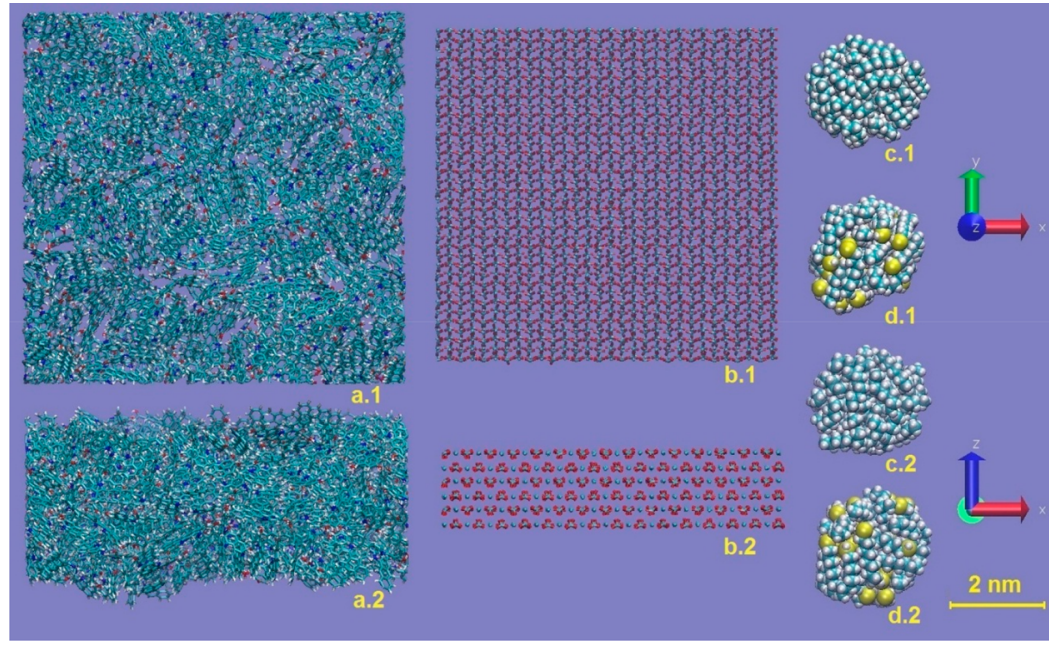

Figure 3. Kerogen slab (a), calcite (104) slab (b), 30-molecule non-polar oil cluster (c), and 30-molecule polar oil cluster (d). "x.1" and "x.2" denote different orientations.

To capture fundamental properties of kerogen, we employed a molecular fragment $\mathrm{C}_{22} \mathrm{H}_{13} \mathrm{ON}$ directly derived from type II kerogen to build kerogen surfaces, ${ }^{37}$ which is the most common kerogen in hydrocarbon-bearing shale formations. ${ }^{64}$ The kerogen molecule has five benzene rings, a secondary amine, and a phenol group, making this kerogen molecule a polar compound. To create kerogen surfaces, a computational supercell containing a layer of frozen dummy atoms and 511 randomly added kerogen molecules (18907 atoms in total) was quenched from 3000 to $300 \mathrm{~K}$ using an NPT ensemble. The surface was then created by removing the dummy atoms sandwiched by the kerogen aggregate, followed by a stabilization and a relaxation of the surface at $300 \mathrm{~K}$ using an NVT ensemble.

The calcite (104) surface in Figure $3 \mathrm{~b}$ was built with $1620 \mathrm{CaCO}_{3}$ molecule units with a dimension of approximately $7 \mathrm{~nm} \times 7 \mathrm{~nm} \times 2$ $\mathrm{nm}$ with 8100 atoms. The kerogen surface in Figure $3 \mathrm{a}$ was built with $511 \mathrm{C}_{22} \mathrm{H}_{13} \mathrm{ON}$ molecule units with a dimension of approximately 8 $\mathrm{nm} \times 8 \mathrm{~nm} \times 3 \mathrm{~nm}$ with 18907 atoms. Because of the ubiquitous presence of water in the reservoir formations, water molecules were added to the fluid. To ensure the oil molecules were surrounded by water, 7250 and 10000 water molecules were added to the calcite surface of single oil molecule or oil cluster, respectively, while 7500 and 10000 water molecules were placed on kerogen surfaces of single oil molecule or oil cluster, respectively.

A previous experimental study indicates that the calcite (104) surface exhibits a neutral charge due to the stoichiometry and alternating of $\mathrm{Ca}^{2+}$ and $\mathrm{CO}_{3}{ }^{2-72,73}$ Kerogen surfaces can be negatively charged due to the deprotonation of functional groups, such as $\mathrm{OH}$ and $\mathrm{NH}$. However, classical MD models only simulate interatomic interactions by empirical potentials for bond length, angle, and dihedral, whereas formation and breaking of covalent bonds are not considered unless specified by force field. Both calcite and kerogen surfaces maintain electrical neutrality, owing to the charge balance of each model molecule. Layers of alternating $\mathrm{Ca}^{2+}$ and $\mathrm{CO}_{3}{ }^{2-}$ on the calcite (104) create a flat surface, while the benzene rings and polar functional groups of kerogen molecule yield highly heterogeneous surfaces of kerogen.

Molecular Dynamics (MD) Simulation and Gibbs Free Energy Profiles. MD simulations in this study were deployed using the software package GROningen MAchine for Chemical Simulations (GROMACS). ${ }^{94}$ All simulations employed three-dimensional periodic boundary conditions. The OPLS-AA force field was used to describe oil molecules and kerogen. ${ }^{75}$ The SPC potential is used to describe the water molecule. ${ }^{76}$ A previously developed force field was used for calcite. ${ }^{77}$ All these potentials have been tested and are capable of producing satisfactory results on bulk and interfacial properties, which are consistent with experimental data. ${ }^{78-80}$ Newton's equations of motion were integrated using the leapfrog scheme with a time step of $1 \mathrm{fs}$, fast smooth particle-mesh Ewald (SPME) electrostatics, Verlet cutoff-scheme, and temperature coupling using a Nosé-Hoover extended ensemble with a coupling constant of 0.1 ps. Simulations were visualized by visual molecular dynamics (VMD) package. ${ }^{81}$

The potential of mean force for the oil interactions with different surfaces was computed by umbrella sampling and the weighted histogram analysis method (WHAM) ${ }^{82,83}$ The Gromacs package was used to carry out umbrella sampling simulations by running separate simulation windows along the reaction coordinate individually. These windows were generated by extracting a series of configurations from a pulling simulation that drew the oil into or away from the surfaces along the designated reaction coordinate.

In each simulation window, umbrella potential, a biased harmonic potential, was applied to the system. For each individual simulation window, a constraint potential with a force constant $9000 \mathrm{~kJ} \cdot \mathrm{mol}^{-1}$. $\mathrm{nm}^{-1}$ for $0.1 \mathrm{~ns}$ to equilibrate the system was first applied, then an umbrella potential with a force constant $9000 \mathrm{~kJ} \cdot \mathrm{mol}^{-1} \cdot \mathrm{nm}^{-2}$ was deployed for $0.1 \mathrm{~ns}$ up to $0.2 \mathrm{~ns}$ to obtain probability distribution of the given reaction coordinate. With enough sampling overlaps between simulation windows in the entire reaction coordinate space, a free energy profile curve can be calculated by combining data from each window using WHAM. ${ }^{82,84}$

An analysis routine to estimate the errors of the energy profiles was developed using LOESS algorithm in RStudio. ${ }^{85,86}$ This method took the energy profile and employed the bootstrap technique to calculate the confidential intervals at $95 \%$ confidence level. The computed errors are listed as shown in Table 1 denoted by brackets. The fluctuation of free energy profile, as shown in Figure S1, is consistent with the size of the estimated error bar.

\section{RESULTS AND DISCUSSION}

The free energy surfaces in Figures 4-7 show how the system energy changes as a function of the distance between oil compounds and surfaces with respect to their centers of mass (COM). For instance, if an oil molecule was adsorbed onto a 2 $\mathrm{nm}$ thick calcite surface under periodic boundary conditions, the COM distance between the adsorbed oil and the calcite surface would be approximately $1 \mathrm{~nm}$. When the oils molecules are close to the surface, the energy increases due to repulsive interactions. When the oils gradually move away from the surface, the energy first reaches a minimum point, at which the adsorption occurs at the surfaces. An absence of the minimum suggests both adsorption and desorption cannot occur at the interface of interest. As the distance continuously increases, the 
Table 1. Desorption Energy of Single Molecule Oil Droplet and 30-Molecule Oil Drop on Calcite and Kerogen Surfaces under $300 \mathrm{~K}^{a}$

\begin{tabular}{|c|c|c|c|c|c|}
\hline \multicolumn{2}{|c|}{$\begin{array}{l}\text { desorption energy } \\
(\mathrm{kJ} / \mathrm{mol})\end{array}$} & \multirow{2}{*}{$\begin{array}{c}\text { kerogen with } \\
\text { water }\end{array}$} & \multirow{2}{*}{$\begin{array}{r}\text { kerogen } \\
23.3(3.5)\end{array}$} & \multirow{2}{*}{$\begin{array}{c}\text { calcite } \\
\text { with } \\
\text { water } \\
0\end{array}$} & \multirow{2}{*}{$\begin{array}{c}\text { calcite } \\
18.0(5.5)\end{array}$} \\
\hline $\begin{array}{l}\text { non- } \\
\text { polar }\end{array}$ & $\begin{array}{l}\text { single } \\
\text { molecule }\end{array}$ & & & & \\
\hline & $\begin{array}{l}\text { cluster: } \\
\text { total }\end{array}$ & $372(13.8)$ & $438(13.5)$ & 0 & $198(42)$ \\
\hline & $\begin{array}{l}\text { cluster: } \\
\text { per } \\
\text { molecule }\end{array}$ & $12.4(0.46)$ & $14.6(0.45)$ & 0 & $6.6(1.4)$ \\
\hline \multirow[t]{3}{*}{$\begin{array}{c}\text { polar } \\
\text { oil }\end{array}$} & $\begin{array}{l}\text { single } \\
\text { molecule }\end{array}$ & $16.5(3.3)$ & $39.5(9.5)$ & 0 & $33.6(3.9)$ \\
\hline & $\begin{array}{l}\text { cluster: } \\
\text { total }\end{array}$ & $210(11.4)$ & $438(13.5)$ & 0 & $222(36)$ \\
\hline & $\begin{array}{l}\text { cluster: } \\
\text { per } \\
\text { molecule }\end{array}$ & $7.0(0.38)$ & $14.6(0.45)$ & 0 & $7.4(1.2)$ \\
\hline
\end{tabular}

${ }^{a_{T}}$ The () denotes the errors propagated from the output data of WHAM.

energy increases until the system reaches the energy plateau where no additional energy is required to desorb the oil molecules from the surfaces.

Interactions of Oil Molecules with Kerogen Surface. The free energy profiles in Figure 4 and Table 1 show the energy changes as a function of the distance between oil compounds and kerogen surface in the presence of water. The desorption energies are $17.0 \pm 2.0$ and $16.5 \pm 3.3 \mathrm{~kJ} / \mathrm{mol}$ for non-polar and polar single oil molecule and $371 \pm 12.4$ and $209 \pm 7.0 \mathrm{~kJ} / \mathrm{mol}$ for non-polar and polar oil clusters, respectively. In the absence of water, it is challenging to maintain oil molecules as a cluster at or above $300 \mathrm{~K}$. To stabilize the oil cluster, a series of umbrella sampling simulations were carried out under lower system temperatures to extrapolate the desorption energy to $300 \mathrm{~K}$ (more details in Figure S3). The desorption energies of the oil clusters on kerogen surfaces are $437 \pm 13.5 \mathrm{~kJ} / \mathrm{mol}$ for both polar and non-polar (Figure S3). For the single oil molecule, the desorption energies on kerogen in Figure 6 and Table 1 are $23.3 \pm 3.5$ and $39.5 \pm 9.5 \mathrm{~kJ} / \mathrm{mol}$ for non-polar and polar, respectively.

Interactions of Oil Molecules with Calcite (104) Surface. The free energy profiles in Figure 7 show how free energy changes as a function of the distance between oil compounds and the calcite (104) surface in water. Unlike the rest free energy profiles (described later), they exhibit a distinct pattern: As the distance increases, the free energy quickly decreases and then stays at the same value as the molecule is further away from the surface. Such patterns indicate oil cannot be adsorbed onto the calcite surface in the presence of water.

For comparison, the same systems without water were simulated, of which the free energy profiles are depicted in Figure 5. The results show that $33.6 \pm 3.9$ and $18.0 \pm 5.5 \mathrm{~kJ} /$ mol are required to desorb polar and non-polar oil molecules from the calcite surfaces, respectively, and $222 \pm 36$ and $198 \pm$ $42 \mathrm{~kJ} / \mathrm{mol}$ to desorb polar and non-polar oil clusters, respectively. A detailed analysis of the trajectory (Figure S4) suggests that the polar molecule was bound to the calcite surface through the thiol functional group $-\mathrm{SH}$, which confirms a previous study on the adsorption of simple organic molecules on calcite (104). ${ }^{87}$ In addition, the thiol group - SH of polar oil appears to favor the sites of $\mathrm{Ca}^{2+}$ site of calcite (104) surface, whereas the non-polar oil shows no preference of absorption sites.

Effect of Surface Composition on the Interaction Energy. Our study shows that, in general, oil molecules have stronger interactions with kerogen than with calcite regardless of surface environment and oil molecular polarity. Kerogen is an organic compound and usually oleophilic, whose surface property depends on the specific functional groups. The kerogen model in this study contains functional groups such as hydroxyl $(-\mathrm{OH})$ and thiol (sulfhydryl, $-\mathrm{SH})$, which inherently exhibit a strong affinity with hydrophilic surfaces while the rest strongly interact with hydrophobic surfaces. On the contrary, calcite, especially the (104) face, is strongly hydrophilic with ionic species $\mathrm{Ca}^{2+}$ and $\mathrm{CO}_{3}{ }^{2-}$ on the surface. Therefore, oil molecules can be more easily adsorbed onto kerogen than calcite, giving a higher level of energy for oil interactions with a kerogen surface. Another factor that contributes to the difference between kerogen and calcite is the surface area: Calcite has a low surface area, which weakens its sorption capacity, ${ }^{88}$ whereas kerogen is porous and waxy according to experimental observations. ${ }^{64,89}$ Thus, the effective surface area on kerogen would be much higher than on calcite, leading to a higher sorption capacity.

As a result of their different surface properties, the desorption energy at the kerogen surface is higher than that at the calcite surface: 5.3 to $17 \mathrm{~kJ} / \mathrm{mol}$ higher for a single oil molecule and 210 to $372 \mathrm{~kJ} / \mathrm{mol}$ higher for the oil cluster (7.0-12.4 kJ/mol per molecule for the oil cluster). The difference in the desorption energies of both single molecule oil and oil cluster implies that oil recovery from organic phases of reservoir rock can take more energy than from these highly hydrophilic surfaces of inorganic mineral phases such as calcite.
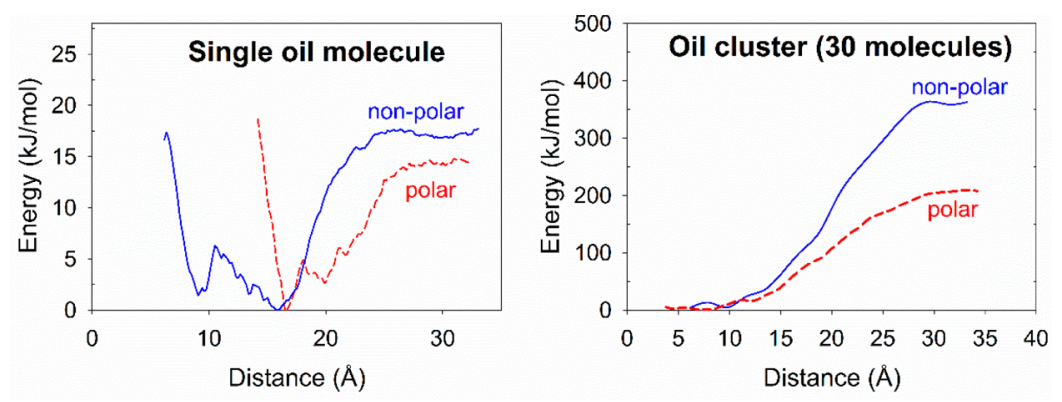

Figure 4. Free energy surfaces of single molecule of polar or non-polar oil on kerogen surface with water (left). Free energy surfaces of cluster of 30 polar or non-polar oil molecules on kerogen surface with water (right). 

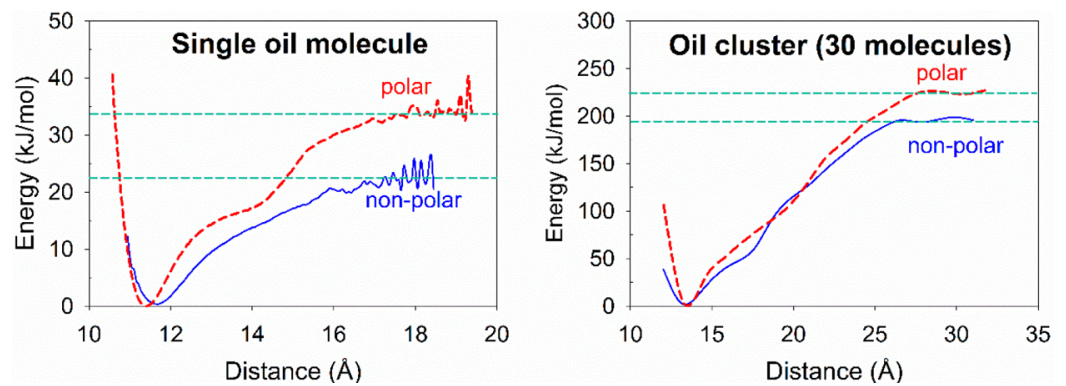

Figure 5. Free energy surfaces of single molecule of polar or non-polar oil on calcite surface without water (left). Free energy surfaces of cluster of 30 polar or non-polar oil molecules on calcite surface without water (right).
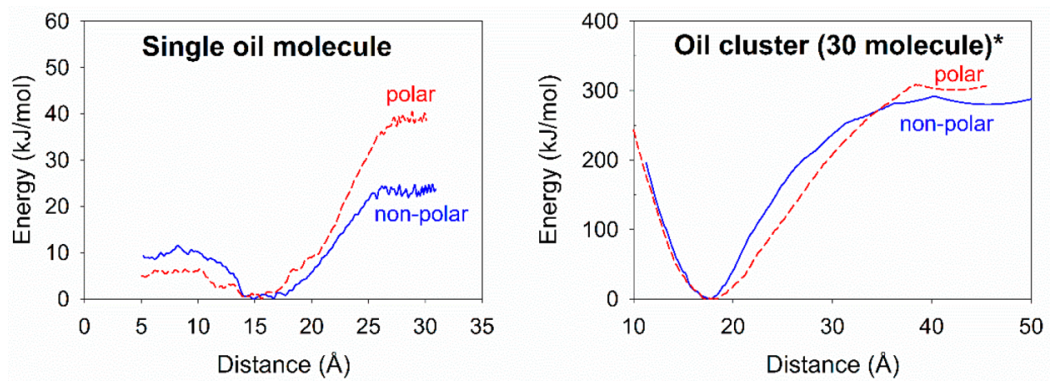

Figure 6. Free energy surfaces of single molecule of polar and non-polar oil on kerogen surface without water (left). Free energy surfaces of cluster of 30 polar or non-polar oil molecules on kerogen surface without water (right). *indicates the simulations were prepared at $200 \mathrm{~K}$ due to the technical issues as described in the discussion.
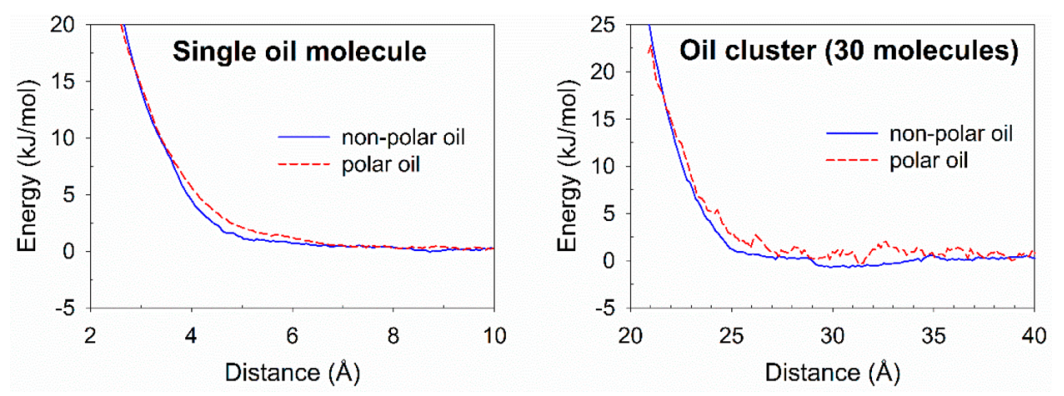

Figure 7. Free energy surfaces of single molecule and cluster of 30 polar or non-polar oil molecules on calcite surface in the presence of water.

Effect of Molecular Polarity. At the kerogen surface, molecular polarity plays an imperative role in the energetics. These phenomena can be explained by the dipole interactions. Since there is no free ion in the systems, the intermolecular interactions are dominated by permanent dipole interaction, or Keesom interaction. As shown in Figure S5a,c, the thiol functional group $(-\mathrm{SH}$, yellow) of the polar oil prefers to stay in close proximity to the functional groups of kerogen molecules such as amine (-NH-, blue) and hydroxyl $(-\mathrm{OH}, \mathrm{red})$ upon contact at the interface, which confirms the expected dipole interactions. Unlike the polar oil, nonpolar oil molecules have no dipole moment, therefore a weaker interaction energy than that of the polar oil molecules is expected. Thus, the interactions of the polar oil molecule with kerogen surface is stronger than those of non-polar. ${ }^{90}$ As shown in the Table 1, recovering the polar oil molecule requires energy about two times the energy of non-polar per molecule in the absence of water. The required energies to recover single polar and non-polar oil molecules are approximately the same in the presence of water. For the oil cluster, our calculation indicates that the minimal amount of energy required to recover the polar oil cluster is comparable to that of the non-polar oil cluster if water is absent. However, in the presence of water, the polar oil cluster requires approximately half of the energy than that to recover the non-polar oil cluster. These results suggest that the effect of polarity is complicated by kerogen surface property and the presence of water.

At the calcite (104) surface, polar oil molecules consistently require higher energy for recovery than that of its counterpart non-polar oil, owing to the molecular dipole of the polar oil and the hydrophilic nature of the calcite surface. Although previous studies suggested that calcite (104) is overall nonpolar because the alternating $\mathrm{Ca}^{2+}$ and $\mathrm{CO}_{3}{ }^{2-}$ are closely packed and charge balance is maintained, ${ }^{91,92}$ the electrostatic interaction between ionic species at the calcite surface and the functional group at the polar molecule favors the adsorption of the polar oil molecules. Therefore, the required energy to recover the polar oil molecule from calcite is approximately two times of that for the non-polar oil molecule, and the energy required by the polar oil molecular cluster is approximately $10 \%$ higher than that for the non-polar oil cluster in the absence of water. 
Effect of Surface Water. Our study shows that the presence of surface water reduces the energy minimum to recover oil from all surface conditions. As discussed previously, the calcite surface is hydrophilic, while kerogen is both hydrophilic and hydrophobic. The surface water can easily be attracted to the calcite surface and kerogen hydrophilic functional groups. Both water and polar oil molecules have similar dipole moments 2.27 and $2.9 \mathrm{D},{ }^{59,76}$ respectively. Water molecules compete with polar oil molecules for adsorption at surfaces with a hydrophilic character, consequently reducing the energy minimum to recover the oil molecules at the surface. The interactions of waters with the calcite (104) surfaces were much stronger than with kerogen surfaces, suggesting a weaker hydrophilic nature of kerogen surface than that of the calcite surface. The affinity between calcite and water is stronger than that between calcite and oil, resulting in a strong oil-repellent surface of calcite in the presence of water. As shown in Table 1, the kerogen surface with water requires much lower energies to desorb oil. For polar oil, the surface water brought a reduction of $50 \%-60 \%$ on energy minimum to recover a polar oil compound and $15 \%-30 \%$ reduction for a non-polar oil compound. The energy differences between nonpolar and polar oil also demonstrate the crucial role of molecular polarity on the fluid-rock interactions. Given the strong hydrophilicity of calcite, the calcite surface becomes oleophobic, jettisoning all the surface oil, in the presence of water. Additionally, the radial distribution of water-surface atom pair distance (Figure S6) shows several peaks for both water-calcite and water-kerogen interfaces, indicating the formation of organized water structures. Among all the RDF peaks within the range of $10 \AA$, the first peaks for waterkerogen and water-calcite occurred at 1.7 and $1.8 \AA$, respectively. Overall, the $\mathrm{RDF}$ peaks at the water-calcite interface are significantly higher than those at water-kerogen, suggesting strong interfacial interactions between water and calcite. These results provide a fundamental understanding of the decisive role that water plays in the oil-rock interactions during oil recovery.

Effect of Oil Clustering. Our study shows that recovering oil clusters requires lower energy per molecule than a single oil molecule. For instance, the energy minimum to recover a single molecule of polar oil is $4.6-25.2 \mathrm{~kJ} / \mathrm{mol}$ higher than the energy per molecule of the oil cluster, which is an increase of $37 \%$ to $340 \%$ of the energy per molecule of the oil cluster. This difference is mainly caused by the number of oil molecules that directly interact with the surface. While the single molecule always interacts with the surfaces, not all the molecules in the 30-molecule clusters directly interact with the surfaces, which lowers the energy minimum per molecule to recover a molecular cluster. Although the oil molecular clusters are too small to be comparable with oils in the porous medium in reservoir rocks, the trend quantified in this study suggests that as the cluster size decreases, recovering the oil confined in the pores becomes more challenging.

\section{CONCLUSIONS}

This study demonstrated that the molecular dynamics simulation is capable of calculating the free energy surface for fluid-rock interactions involving single oil molecules, oil molecular clusters, and calcite (104) and kerogen surfaces. The results provide fundamental understandings of the interfacial interactions and valuable implications for oil recovery in reservoirs. The main conclusions are as follows.
(1) The hydrophobicity of the surface of reservoir materials has a significant effect on the oil-rock interactions, leading to a higher free energy cost for oil displacement from organic phases of reservoir rock than that from the highly hydrophilic surfaces of inorganic mineral phases such as calcite.

(2) The polarity of oil molecules strongly affects the interfacial interactions at both the kerogen and calcite surfaces. The polar oil molecules require more energy to be recovered from both surfaces than non-polar ones. For complex hydrocarbon fluid systems, having a large portion of polar compounds in the oil poses a great challenge. In order to effectively model the interactions between oil and the reservoir materials and to produce reliable results, an accurate description of the polarity of oil molecules is necessary.

(3) Surface water profoundly influences the interactions between oil molecules and reservoir materials. Because of its large dipole moment, water facilitates the oil recovery process by interacting with hydrophilic surfaces or sites of either organic kerogen or inorganic minerals.

(4) Single oil molecules or small oil molecule clusters dispersed in small nanopores tend to be more challenging to be recovered than large oil molecular clusters due to the stronger interactions of oil molecules with the surfaces.

The success of implementing the free energy methods to study these simple hydrocarbon systems paves the way for building more realistic simulations of complex systems by varying temperatures, adding fluid components (e.g., electrolytes, methane, carbon dioxide, and large oil compounds), and introducing other major inorganic phases such as clay minerals and quartz.

\section{ASSOCIATED CONTENT}

\section{(s) Supporting Information}

The Supporting Information is available free of charge at https://pubs.acs.org/doi/10.1021/acs.energyfuels.0c00053.

Discussions of code for error estimation and video links of pertinent simulation trajectories, additional figures of free energy surfaces, snapshot of the simulation trajectories, and water-surface radial distribution, tables of desorption energies PDF)

\section{AUTHOR INFORMATION}

\section{Corresponding Author}

Zelong Zhang - Department of Geology and Geophysics, Louisiana State University, Baton Rouge, Louisiana 70803, United States; 이이.org/0000-0002-0807-8991; Email: zelongz@lsu.edu

\section{Authors}

Haoran Liu - Department of Experimental Statistics and Department of Oceanography and Coastal Sciences, Louisiana State University, Baton Rouge, Louisiana 70803, United States; ○ orcid.org/0000-0003-0955-3552

Jianwei Wang - Department of Geology and Geophysics and Center for Computation and Technology, Louisiana State University, Baton Rouge, Louisiana 70803, United States; (1) orcid.org/0000-0001-7671-0533

Complete contact information is available at: https://pubs.acs.org/10.1021/acs.energyfuels.0c00053 


\section{Notes}

The authors declare no competing financial interest.

\section{ACKNOWLEDGMENTS}

Z.Z. thanks Dr. Tim J. Tambach (Shell Global Solutions, The Netherlands), Dr. Chunjiang Wang (China University of Petroleum - Beijing, China), and Dr. Erdem Idiz (University of Oxford, UK) for their inspiration to start this project and valuable discussions regarding the scientific challenges in reservoir geochemistry. This research used resources of the National Energy Research Scientific Computing Center (NERSC), a U.S. Department of Energy Office of Science User Facility operated under Contract No. DE-AC0205CH11231. Portions of this research were conducted with high performance computing resources provided by Louisiana State University (http://www.hpc.lsu.edu).

\section{REFERENCES}

(1) Annual Energy Outlook 2019; AEO2019; U.S. Energy Information Administration: Washington, DC, 2019.

(2) Thomas, S. Enhanced Oil Recovery - An Overview. Oil Gas Sci. Technol. 2008, 63 (1), 9-19.

(3) Forbes, P. The Status of Core Analysis. J. Pet. Sci. Eng. 1998, 19 (1), 1-6.

(4) Gao, B.; Kralik, J.; Vo, L.; Shebl, H.; Al Shehhi, R.; Al Jawhari, M. O.; Fullmer, S. State of the Art Special Core Analysis Program Design and Results for a Middle Eastern Carbonate Reservoir; Society of Petroleum Engineers, 2015.

(5) van der Weerd, H.; Masalmeh, S. K.; Jing, X. D.; van Vark, W.; Christiansen, S.; Van Dorp, J. Impact of SCAL (Special Core Analysis) on Carbonate Reservoirs: How Capillary Forces Can Affect Field Performance Predictions. Petrophysics 2004, 45 (05), pp 403413.

(6) Cueto-Felgueroso, L.; Juanes, R. Forecasting Long-Term Gas Production from Shale. Proc. Natl. Acad. Sci. U. S. A. 2013, 110 (49), 19660-19661.

(7) Zhang, T.; Ellis, G. S.; Ruppel, S. C.; Milliken, K.; Yang, R. Effect of Organic-Matter Type and Thermal Maturity on Methane Adsorption in Shale-Gas Systems. Org. Geochem. 2012, 47, 120-131.

(8) Hutton, A. C.; Kantsler, A. J.; Cook, A. C.; McKirdy, D. M. Organic Matter in Oil Shales. APPEA J. 1980, 20 (1), 44-67.

(9) Ross, D. J. K.; Marc Bustin, R. The Importance of Shale Composition and Pore Structure upon Gas Storage Potential of Shale Gas Reservoirs. Mar. Pet. Geol. 2009, 26 (6), 916-927.

(10) Loucks, R. G.; Reed, R. M.; Ruppel, S. C.; Hammes, U. Spectrum of Pore Types and Networks in Mudrocks and a Descriptive Classification for Matrix-Related Mudrock Pores Spectrum of Pore Types and Networks In Mudrocks. AAPG Bull. 2012, 96 (6), 10711098.

(11) Sondergeld, C. H.; Ambrose, R. J.; Rai, C. S.; Moncrieff, J. Micro-Structural Studies of Gas Shales; Society of Petroleum Engineers, 2010.

(12) Clarkson, C. R.; Solano, N.; Bustin, R. M.; Bustin, A. M. M.; Chalmers, G. R. L.; He, L.; Melnichenko, Y. B.; Radliński, A. P.; Blach, T. P. Pore Structure Characterization of North American Shale Gas Reservoirs Using USANS/SANS, Gas Adsorption, and Mercury Intrusion. Fuel 2013, 103, 606-616.

(13) Passey, Q. R.; Bohacs, K.; Esch, W. L.; Klimentidis, R.; Sinha, S. From Oil-Prone Source Rock to Gas-Producing Shale Reservoir - Geologic and Petrophysical Characterization of Unconventional Shale Gas Reservoirs; Society of Petroleum Engineers, 2010.

(14) Vernik, L.; Milovac, J. Rock Physics of Organic Shales. Lead. Edge 2011, 30 (3), 318-323.

(15) Milliken, K. L.; Rudnicki, M.; Awwiller, D. N.; Zhang, T. Organic Matter-Hosted Pore System, Marcellus Formation (Devonian), Pennsylvania Geohorizon. AAPG Bull. 2013, 97 (2), 177-200.
(16) Shabro, V.; Torres-Verdin, C.; Javadpour, F. Numerical Simulation of Shale-Gas Production: From Pore-Scale Modeling of SlipFlow, Knudsen Diffusion, and Langmuir Desorption to Reservoir Modeling of Compressible Fluid; Society of Petroleum Engineers, 2011.

(17) Wu, K.; Li, X.; Wang, C.; Yu, W.; Chen, Z. Model for Surface Diffusion of Adsorbed Gas in Nanopores of Shale Gas Reservoirs. Ind. Eng. Chem. Res. 2015, 54 (12), 3225-3236.

(18) Wang, F. P.; Reed, R. M. Pore Networks and Fluid Flow in Gas Shales; Society of Petroleum Engineers, 2009.

(19) Zaera, F. Probing Liquid/Solid Interfaces at the Molecular Level. Chem. Rev. 2012, 112 (5), 2920-2986.

(20) Surface Analysis Methods in Materials Science. In Springer Series in Surface Sciences; O'Connor, J., Sexton, B., Smart, R., Eds.; Springer-Verlag: Berlin, Germany, 1992.

(21) Hochella, M. F.; White, A. F. Mineral-Water Interface Geochemistry; Walter de Gruyter GmbH \& Co KG: Berlin, 2018; Vol. 23.

(22) Milner, M.; McLin, R.; Petriello, J. Imaging Texture and Porosity in Mudstones and Shales: Comparison of Secondary and Ion-Milled Backscatter SEM Methods; Society of Petroleum Engineers, 2010.

(23) Curtis, M. E.; Ambrose, R. J.; Sondergeld, C. H.; Rai, C. S. Transmission and Scanning Electron Microscopy Investigation of Pore Connectivity of Gas Shales on the Nanoscale; Society of Petroleum Engineers, 2011.

(24) Bernard, S.; Horsfield, B.; Schulz, H.-M.; Wirth, R.; Schreiber, A.; Sherwood, N. Geochemical Evolution of Organic-Rich Shales with Increasing Maturity: A STXM and TEM Study of the Posidonia Shale (Lower Toarcian, Northern Germany). Mar. Pet. Geol. 2012, 31 (1), $70-89$.

(25) Javadpour, F. Nanopores and Apparent Permeability of Gas Flow in Mudrocks (Shales and Siltstone). J. Can. Pet. Technol. 2009, 48 (08), 16-21.

(26) Javadpour, F.; Moravvej Farshi, M.; Amrein, M. Atomic-Force Microscopy: A New Tool for Gas-Shale Characterization. J. Can. Pet. Technol. 2012, 51 (04), 236-243.

(27) Bhargava, S.; Awaja, F.; Subasinghe, N. D. Characterisation of Some Australian Oil Shale Using Thermal, X-Ray and IR Techniques. Fuel 2005, 84 (6), 707-715.

(28) Elgmati, M. M.; Zhang, H.; Bai, B.; Flori, R. E.; Qu, Q. Submicron-Pore Characterization of Shale Gas Plays; Society of Petroleum Engineers, 2011.

(29) Tiwari, P.; Deo, M.; Lin, C. L.; Miller, J. D. Characterization of Oil Shale Pore Structure before and after Pyrolysis by Using X-Ray Micro CT. Fuel 2013, 107, 547-554.

(30) Duliu, O. G. Computer Axial Tomography in Geosciences: An Overview. Earth-Sci. Rev. 1999, 48 (4), 265-281.

(31) Kadayam Viswanathan, R. K.; Cao Minh, C.; Zielinski, L.; Vissapragada, B.; Akkurt, R.; Song, Y.-Q.; Liu, C.; Jones, S.; Blair, E. Characterization of Gas Dynamics in Kerogen Nanopores by NMR; Society of Petroleum Engineers, 2011.

(32) Korb, J.-P.; Nicot, B.; Louis-Joseph, A.; Bubici, S.; Ferrante, G. Dynamics and Wettability of Oil and Water in Oil Shales. J. Phys. Chem. C 2014, 118 (40), 23212-23218.

(33) Cygan, R. T. Molecular Modeling in Mineralogy and Geochemistry. Rev. Mineral. Geochem. 2001, 42 (1), 1-35.

(34) Allen, M.; Tildesley, D. Computer Simulation of Liquids, 2 ed.; Oxford University Press: Oxford, NY, 2017.

(35) Frenkel, D.; Smit, B. Understanding Molecular Simulation: From Algorithms to Applications, 2 ed.; Academic Press: San Diego, CA, 2002.

(36) Falk, K.; Coasne, B.; Pellenq, R.; Ulm, F.-J.; Bocquet, L. Subcontinuum Mass Transport of Condensed Hydrocarbons in Nanoporous Media. Nat. Commun. 2015, 6, 6949.

(37) Collell, J.; Galliero, G.; Gouth, F.; Montel, F.; Pujol, M.; Ungerer, P.; Yiannourakou, M. Molecular Simulation and Modelisation of Methane/Ethane Mixtures Adsorption onto a Microporous Molecular Model of Kerogen under Typical Reservoir Conditions. Microporous Mesoporous Mater. 2014, 197, 194-203. 
(38) Collell, J.; Galliero, G.; Vermorel, R.; Ungerer, P.; Yiannourakou, M.; Montel, F.; Pujol, M. Transport of Multicomponent Hydrocarbon Mixtures in Shale Organic Matter by Molecular Simulations. J. Phys. Chem. C 2015, 119 (39), 2258722595.

(39) Collell, J.; Ungerer, P.; Galliero, G.; Yiannourakou, M.; Montel, F.; Pujol, M. Molecular Simulation of Bulk Organic Matter in Type II Shales in the Middle of the Oil Formation Window. Energy Fuels 2014, 28 (12), 7457-7466.

(40) Sui, H.; Yao, J. Effect of Surface Chemistry for $\mathrm{CH} 4 / \mathrm{CO} 2$ Adsorption in Kerogen: A Molecular Simulation Study. J. Nat. Gas Sci. Eng. 2016, 31, 738-746.

(41) Yiannourakou, M.; Ungerer, P.; Leblanc, B.; Rozanska, X.; Saxe, P.; Vidal-Gilbert, S.; Gouth, F.; Montel, F. Molecular Simulation of Adsorption in Microporous Materials. Oil Gas Sci. Technol. 2013, 68 (6), 977-994.

(42) Lee, T.; Bocquet, L.; Coasne, B. Activated Desorption at Heterogeneous Interfaces and Long-Time Kinetics of Hydrocarbon Recovery from Nanoporous Media. Nat. Commun. 2016, 7, 11890.

(43) Ambrose, R. J.; Hartman, R. C.; Diaz-Campos, M.; Akkutlu, I. Y.; Sondergeld, C. H. Shale Gas-in-Place Calculations Part I: New Pore-Scale Considerations. SPE J. 2012, 17 (01), 219-229.

(44) Wang, S.; Javadpour, F.; Feng, Q. Molecular Dynamics Simulations of Oil Transport through Inorganic Nanopores in Shale. Fuel 2016, 171, 74-86.

(45) Wang, S.; Feng, Q.; Javadpour, F.; Yang, Y.-B. Breakdown of Fast Mass Transport of Methane through Calcite Nanopores. J. Phys. Chem. C 2016, 120 (26), 14260-14269.

(46) Zheng, H.; Du, Y.; Xue, Q.; Zhu, L.; Li, X.; Lu, S.; Jin, Y. Surface Effect on Oil Transportation in Nanochannel: A Molecular Dynamics Study. Nanoscale Res. Lett. 2017, 12 (1), 413.

(47) Underwood, T.; Erastova, V.; Cubillas, P.; Greenwell, H. C. Molecular Dynamic Simulations of Montmorillonite-Organic Interactions under Varying Salinity: An Insight into Enhanced Oil Recovery. J. Phys. Chem. C 2015, 119 (13), 7282-7294.

(48) Liu, Q.; Yuan, S.; Yan, H.; Zhao, X. Mechanism of Oil Detachment from a Silica Surface in Aqueous Surfactant Solutions: Molecular Dynamics Simulations. J. Phys. Chem. B 2012, 116 (9), 2867-2875.

(49) Kästner, J. Umbrella Sampling. Wiley Interdiscip. Rev. Comput. Mol. Sci. 2011, 1 (6), 932-942.

(50) Hughey, C. A.; Rodgers, R. P.; Marshall, A. G.; Qian, K.; Robbins, W. K. Identification of Acidic NSO Compounds in Crude Oils of Different Geochemical Origins by Negative Ion Electrospray Fourier Transform Ion Cyclotron Resonance Mass Spectrometry. Org. Geochem. 2002, 33 (7), 743-759.

(51) Hyne, N. J. Nontechnical Guide to Petroleum Geology, Exploration, Drilling, and Production; PennWell Corporation: Tulsa, OK, 2012.

(52) Jarvie, D. M. Shale Resource Systems for Oil and Gas: Part 2Shale-Oil Resource Systems. American Association of Petroleum Geologists 2012, 89-119.

(53) Buckley, J. S.; Liu, Y.; Monsterleet, S. Mechanisms of Wetting Alteration by Crude Oils. SPE J. 1998, 3 (01), 54-61.

(54) Sayyouh, M. H.; Hemeida, A. M.; Al-Blehed, M. S.; Desouky, S. M. Role of Polar Compounds in Crude Oils on Rock Wettability. J. Pet. Sci. Eng. 1991, 6 (3), 225-233.

(55) Speight, J. G. The Chemical and Physical Structure of Petroleum: Effects on Recovery Operations. J. Pet. Sci. Eng. 1999, 22 (1), 3-15.

(56) Composition, Classification, and Properties of Petroleum. In Chemistry of Fossil Fuels and Biofuels; Schobert, H., Ed.; Cambridge Series in Chemical Engineering; Cambridge University Press: Cambridge, 2013; pp 174-191. .

(57) Mango, F. D. The Light Hydrocarbons in Petroleum: A Critical Review. Org. Geochem. 1997, 26 (7), 417-440.

(58) Yanik, J.; Yüksel, M.; Sağam, M.; Olukçu, N.; Bartle, K.; Frere, B. Characterization of the Oil Fractions of Shale Oil Obtained by
Pyrolysis and Supercritical Water Extraction. Fuel 1995, 74 (1), 4650.

(59) Kvashnin, D. G.; Antipina, L. Y.; Sorokin, P. B.; Tenne, R.; Golberg, D. Theoretical Aspects of WS2 Nanotube Chemical Unzipping. Nanoscale 2014, 6 (14), 8400-8404.

(60) Folk, R. L. Petrology of Sedimentary Rocks; Hemphill Publishing Company, 1980.

(61) Kerisit, S.; Parker, S. C. Free Energy of Adsorption of Water and Metal Ions on the $\{1 \overline{0} 4\}$ Calcite Surface. J. Am. Chem. Soc. 2004, 126 (32), 10152-10161.

(62) Curtis, J. B. Fractured Shale-Gas Systems. AAPG Bull. 2002, 86 (11), 1921-1938.

(63) Jarvie, D. M.; Hill, R. J.; Ruble, T. E.; Pollastro, R. M. Unconventional Shale-Gas Systems: The Mississippian Barnett Shale of North-Central Texas as One Model for Thermogenic Shale-Gas Assessment. AAPG Bull. 2007, 91 (4), 475-499.

(64) Vandenbroucke, M.; Largeau, C. Kerogen Origin, Evolution and Structure. Org. Geochem. 2007, 38 (5), 719-833.

(65) Hu, Y.; Devegowda, D.; Striolo, A.; Phan, A.; Ho, T. A.; Civan, F.; Sigal, R. F. Microscopic Dynamics of Water and Hydrocarbon in Shale-Kerogen Pores of Potentially Mixed Wettability. SPE J. 2014, 20 (01), 112-124.

(66) Firouzi, M.; Rupp, E. C.; Liu, C. W.; Wilcox, J. Molecular Simulation and Experimental Characterization of the Nanoporous Structures of Coal and Gas Shale. Int. J. Coal Geol. 2014, 121, 123128

(67) Falk, K.; Pellenq, R.; Ulm, F. J.; Coasne, B. Effect of Chain Length and Pore Accessibility on Alkane Adsorption in Kerogen. Energy Fuels 2015, 29 (12), 7889-7896.

(68) Ambrose, R. J.; Hartman, R. C.; Diaz Campos, M.; Akkutlu, I. Y.; Sondergeld, C. New Pore-Scale Considerations for Shale Gas in Place Calculations; Society of Petroleum Engineers, 2010. .

(69) Orendt, A. M.; Pimienta, I. S. O.; Badu, S. R.; Solum, M. S.; Pugmire, R. J.; Facelli, J. C.; Locke, D. R.; Chapman, K. W.; Chupas, P. J.; Winans, R. E. Three-Dimensional Structure of the Siskin Green River Oil Shale Kerogen Model: A Comparison between Calculated and Observed Properties. Energy Fuels 2013, 27 (2), 702-710.

(70) Bousige, C.; Ghimbeu, C. M.; Vix-Guterl, C.; Pomerantz, A. E.; Suleimenova, A.; Vaughan, G.; Garbarino, G.; Feygenson, M.; Wildgruber, C.; Ulm, F.-J. Realistic Molecular Model of Kerogen's Nanostructure. Nat. Mater. 2016, 15 (5), 576-582.

(71) Pei, Q.-X.; Zhang, Y.-W.; Shenoy, V. B. Mechanical Properties of Methyl Functionalized Graphene: A Molecular Dynamics Study. Nanotechnology 2010, 21 (11), 115709.

(72) Lee, S. S.; Heberling, F.; Sturchio, N. C.; Eng, P. J.; Fenter, P. Surface Charge of the Calcite (104) Terrace Measured by $\mathrm{Rb}+$ Adsorption in Aqueous Solutions Using Resonant Anomalous X-Ray Reflectivity. J. Phys. Chem. C 2016, 120 (28), 15216-15223.

(73) Wolthers, M.; Tommaso, D. D.; Du, Z.; de Leeuw, N. H. Calcite Surface Structure and Reactivity: Molecular Dynamics Simulations and Macroscopic Surface Modelling of the Calcite Water Interface. Phys. Chem. Chem. Phys. 2012, 14 (43), 1514515157.

(74) Berendsen, H. J. C.; van der Spoel, D.; van Drunen, R. GROMACS: A Message-Passing Parallel Molecular Dynamics Implementation. Comput. Phys. Commun. 1995, 91 (1), 43-56.

(75) Robertson, M. J.; Tirado-Rives, J.; Jorgensen, W. L. Improved Peptide and Protein Torsional Energetics with the OPLS-AA Force Field. J. Chem. Theory Comput. 2015, 11 (7), 3499-3509.

(76) Berendsen, H. J. C.; Postma, J. P. M.; van Gunsteren, W. F.; Hermans, J. Interaction Models for Water in Relation to Protein Hydration. In Intermolecular Forces: Proceedings of the Fourteenth Jerusalem Symposium on Quantum Chemistry and Biochemistry Held in Jerusalem, Israel, April 13-16, 1981; Pullman, B., Ed.; The Jerusalem Symposia on Quantum Chemistry and Biochemistry; Springer Netherlands: Dordrecht, 1981; pp 331-342. .

(77) Raiteri, P.; Gale, J. D.; Quigley, D.; Rodger, P. M. Derivation of an Accurate Force-Field for Simulating the Growth of Calcium 
Carbonate from Aqueous Solution: A New Model for the CalciteWater Interface. J. Phys. Chem. C 2010, 114 (13), 5997-6010.

(78) Geissbühler, P.; Fenter, P.; DiMasi, E.; Srajer, G.; Sorensen, L. B.; Sturchio, N. C. Three-Dimensional Structure of the CalciteWater Interface by Surface X-Ray Scattering. Surf. Sci. 2004, 573 (2), 191-203.

(79) Wolf, G.; Lerchner, J.; Schmidt, H.; Gamsüger, H.; Königsberger, E.; Schmidt, P. Thermodynamics of $\mathrm{CaCO} 3$ Phase Transitions. J. Therm. Anal. 1996, 46 (2), 353-359.

(80) Wolf, G.; Königsberger, E.; Schmidt, H. G.; Königsberger, L.C.; Gamsjäger, H. Thermodynamic Aspects of the Vaterite-Calcite Phase Transition. J. Therm. Anal. Calorim. 2000, 60 (2), 463-472.

(81) Humphrey, W.; Dalke, A.; Schulten, K. VMD: Visual Molecular Dynamics. J. Mol. Graphics 1996, 14 (1), 33-38.

(82) Kumar, S.; Rosenberg, J. M.; Bouzida, D.; Swendsen, R. H.; Kollman, P. A. THE Weighted Histogram Analysis Method for FreeEnergy Calculations on Biomolecules. I. The Method. J. Comput. Chem. 1992, 13 (8), 1011-1021.

(83) Roux, B. The Calculation of the Potential of Mean Force Using Computer Simulations. Comput. Phys. Commun. 1995, 91 (1), 275282.

(84) Hub, J. S.; de Groot, B. L.; van der Spoel, D. G_wham-A Free Weighted Histogram Analysis Implementation Including Robust Error and Autocorrelation Estimates. J. Chem. Theory Comput. 2010, 6 (12), 3713-3720.

(85) Cleveland, W. S. Robust Locally Weighted Regression and Smoothing Scatterplots. J. Am. Stat. Assoc. 1979, 74 (368), 829-836.

(86) R Core Team. R: A Language and Environment for Statistical Computing; R Foundation for Statistical Computing: Vienna, Austria, 2019.

(87) Hakim, S. S.; Olsson, M. H. M.; Sørensen, H. O.; Bovet, N.; Bohr, J.; Feidenhans'l, R.; Stipp, S. L. S. Interactions of the Calcite $\{10.4\}$ Surface with Organic Compounds: Structure and Behaviour at Mineral - Organic Interfaces. Sci. Rep. 2017, 7 (1), 7592.

(88) Ross, D. J. K.; Bustin, R. M. Shale Gas Potential of the Lower Jurassic Gordondale Member, Northeastern British Columbia, Canada. Bull. Can. Pet. Geol. 2007, 55 (1), 51-75.

(89) Loucks, R. G.; Reed, R. M.; Ruppel, S. C.; Jarvie, D. M. Morphology, Genesis, and Distribution of Nanometer-Scale Pores in Siliceous Mudstones of the Mississippian Barnett Shale. J. Sediment. Res. 2009, 79 (12), 848-861.

(90) Madsen, L.; Grahl-Madsen, L.; Grøn, C.; Lind, I.; Engell, J. Adsorption of Polar Aromatic Hydrocarbons on Synthetic Calcite. Org. Geochem. 1996, 24 (12), 1151-1155.

(91) García Carmona, J.; Gómez Morales, J.; Rodríguez Clemente, R. Rhombohedral-Scalenohedral Calcite Transition Produced by Adjusting the Solution Electrical Conductivity in the System $\mathrm{Ca}(\mathrm{OH}) 2-\mathrm{CO} 2-\mathrm{H} 2 \mathrm{O}$. J. Colloid Interface Sci. 2003, 261 (2), 434440.

(92) Shen, J.-W.; Li, C.; van der Vegt, N. F. A.; Peter, C. Understanding the Control of Mineralization by Polyelectrolyte Additives: Simulation of Preferential Binding to Calcite Surfaces. J. Phys. Chem. C 2013, 117 (13), 6904-6913. 